\title{
FORMAÇÃO: UMA ATIVIDADE EM VIAS DE DEFINIÇÃO?*
}

Lucie Tanguy*t

SÍNTESE - A autora aborda o fenômeno da formaçäo enquanto uma atividade que tende a se autonomizar dos processos realizados na instituição escolar e abrange um conjunto de práticas muito heterogêneas segundo os lugares onde são exercidas. Dentre os principais fatos e mudanças associados à formação, destaca: o desemprego, as formas de emprego em ruptura com a norma, o prolongamento da escolaridade e da inserçăo profissional, transiçăo da juventude à vida adulta, análise das politicas educativas e de emprego, qualificaçōes, competências e comparaçōes internacionais.
ABSTRACT - The author approaches the phenomenon of education as an activity which tends to become autonomous from the processes carried out in the educational institution and comprises a set of very heterogeneous practices, according to the places where they are performed. Among the main facts and changes associated with education, the author points out: unemployment, employment forms which break the norm, extension of education and professional insertion, transition from youth to adult life, analysis of educational and job policies, qualifications, competences and intemational comparisons.

\section{Introdução}

Dar conta da literatura que tem por objeto o domínio de pesquisas designado com a etiqueta "formação-emprego" é uma tarefa embaraçosa. O termo de campo freqüentemente utilizado para nomeá-lo talvez o seja de forma abusiva se nos ativermos à definição elaborada por Bourdieu (1992). Deixaremos de lado essa questão, já examinada por Maroy (1991), e diremos brevemente que ele se apresenta como uma constelação de objetos de pesquisa de contornos instáveis e fortemente fixados nos problemas sociais. As noções empregadas para designá-lo são, elas também, flutuantes e de estatuto ainda incerto. A noção de formação, em

- Artigo publicado originalmente em COSTER, Michel de \& PICHAULT, François (org). Traité de Sociologie du Travail. Bélgica: Ed de Boeck-W, 1994. Tradução: Bertilo Brod (Universidade Regional Integrada/URI - Erexim/RS). Revisāo da Tradução: Vanise Pereira Dresch. Revisăo Técnica: Julieta Beatriz Ramos Desaulniers.

- Professora e pesquisadora junto à Universidade Paris X e CNRS - Paris/França.

\begin{tabular}{l|l|l|l|l|l|} 
VERITAS & Porto Alegre & v. 42 & $\mathrm{n}^{2} 2$ & Junho 1997 & p. $385-410$ \\
\hline
\end{tabular}


seu uso extensivo e globalizante, aparece ao lado da noção de educação, ora para se diferenciar muito claramente desta - por exemplo, quando se trata de formação na empresa - ora para entrar em concorrência com ela. Isto ocorre quando se trata de afirmar a centralidade da atividade social de transmissão e de aquisição de conhecimentos, de comportamentos e de atitudes, que não é mais reservada à instituição escolar, ainda que esta continue ocupando um lugar decisivo na sociedade, já que ela acolhe, na França, a quase totalidade dos jovens até os dezoito anos. As mudanças de nome de certos dispositivos institucionais - tais como as unidades de ensino e de pesquisa nas universidades, que se tornaram unidades de formação e de pesquisa - ou de certas revistas - como a do Ministério da Educação Nacional na França, hoje denominada Éducation-Formation e não mais Éducation - não são insignificantes. Exemplos análogos podem ser encontrados em outros países que confirmam o mesmo deslize semântico - training versus vocational education na Grã-Bretanha. A identidade dos domínios designados pelas noções de trabalho e de emprego não parece mais estável. Esta hesitação sobre o sentido das palavras e seu respectivo estatuto se traduz pela sua associação no título de revistas especializadas.' Pesquisadores se empenham em convencer que o deslocamento de interesse do trabalho para o emprego obedece a uma necessidade, não somente porque esse último apresenta problema, mas porque ele "estrutura o trabalho e contribui assim para uma definição do estatuto social, da estratificação e das classes sociais" (Maruani et Reynaud, 1993). A estes pesquisadores, outros respondem que o trabalho no sentido amplo do termo, incluindo 0 trabalho doméstico ou o trabalho social benevolente, continua sendo a experiência social central em torno da qual se efetua a sintese nas sociedade salariais.

Além destas disputas em torno dos nomes e dos territórios que eles designam - territórios onde os pesquisadores têm interesses diferentes - o domínio constituído pelos problemas e pelas pesquisas relativos às rèlações entre esses dois conjuntos de fenômenos que são a formação e o emprego continua sendo um dos mais indefinidos. A substantificação realizada com a denominação de relação formação/emprego em nada diminui esta indefinição. A força do singular não faz senão ocultar a opacidade dos processos e dos fatos cuja compreensão exige reconhecer que eles estão no plural e que não se deixam reduzir à correspondência linear que todo programa político pode anunciar. Na verdade, esse domínio de pesquisa aparece e se desenvolve na base dos problemas sociais que as sociedades industriais conhecem no atual estágio do seu desenvolvimento e do lugar que elas tendem designar aos atributos cognitivos dos indivíduos e à sua formação para resolvê-los. Convocados para apresentar informaçōes e análises, os pesquisadores se apropriam da solicitação que lhes é feita, retraduzem-na em objetos de investigação segundo modalidades que variam de acordo com as disciplinas e os horizontes teóricos das suas especialidades. Tais processos estão na gênese da heterogeneidade de um domínio onde economistas e sociólogos caminham muito próximos um do outro, estabelecem relação sem necessariamente se confrontar.

De início, sublinharemos que as relações entre a formação e o emprego formam uma cadeia tão longa que somente certos elos podem ser identificados e

' Como Travail et emploi, na França; Work, Employment and Society, na Grâ.-Bretanha. 
estudados, aqueles que parecem ser os mais decisivos. Esta seleção de certos lugares e momentos numa cadeia de relações obedece necessariamente a pressupostos, a quadros de referências teóricas já estabelecidos, em resumo, ao julgamento que os investigadores exercem por meio do equipamento intelectual de que dispōem. Isto significa dizer que os objetos de pesquisa assim construídos são o produto de uma tensão entre as coações do questionamento social que obriga os pesquisadores a renovar suas técnicas de investigação, ao mesmo tempo nelas aplicando quadros conceituais e métodos já comprovados. Selecionamos aqui os objetos de pesquisa que nos parecem os mais significativos e representativos deste domínio: por concentrarem um grande número de publicações - inserção e transição para a vida adulta, por exemplo - por expressarem tendências ao desenvolvimento de modos de análise, como o estudo comparativo, que se apresenta particularmente fecundo nesta matéria, ou ainda por traduzirem o deslocamento de problemáticas aplicadas a uma mesma ordem de fenômenos por meio de noções cruzadas, tais como a noção de competência versus a noçäo de qualificação. As pesquisas que se referem à formação nas empresas, que constituem um corpus especifico, se encontram excluídas do nosso exame, uma vez que já foram analisadas por Maroy no presente tratado.

Assim justificada, a apresentação do domínio de pesquisas que não tem a identidade, a estabilidade, a coerência que a duração confere é necessariamente manchada por um certo elemento arbitrário: aquele inerente à percepção do autor, percepção amplamente induzida pela posição deste na sua disciplina. Um tal domínio, diferentemente de outros constituídos de longa data, como o da educação ou o do trabalho, não está organizado por um certo número de idéias fortes compartilhadas e não está atravessado por categorizações relativamente consensuais que dirigem a descrição das observações e as análises de dados. O ponto de vista que baseia esta apresentação se propõe evidenciar, a partir de ângulos de abordagem² diversos, a emergência e o desenvolvimento de uma atividade social de formação que tem a tendência de se separar daquelas que indiretamente a engendraram - a educação e o trabalho - mesmo permanecendo estreitamente ligada a estas, como veremos. Sendo assim, tentaremos, ao longo da exposição, dar conta das diferenças que existem entre abordagens inspiradas na Economia ou na Sociologia, cujas fronteiras, neste campo, nos parecem particularmente pulverizadas e fluidas. É porque umas e outras são confrontadas com os mesmos debates e convocadas a produzir informações e conhecimentos a respeito de questões vivas. Semelhante situação favorece seu relacionamento reciproco tão mais facilmente quanto as questões de filiação e de confronto no seio das disciplinas intelectuais diminuem para dar lugar à idéia de ciências sociais abertas onde novas divisōes se fazem e se desfazem. Todavia, podemos notar uma prevalência dos ângulos de abordagem tomados emprestados da economia, cuja força e legitimidade se impõem numa situação histórica marcada pelo desemprego. Se a questão da classificação por disciplina nos parece tão vazia quanto destituída de pertinência, a ca-

2 Entendemos com isso, à semelhança de Nisbet (1984), "um quadro de análise, uma categoria (no sentido kantiano do termo) que reúne o fato e sua interpretaçăo, a observação do fenômeno e sua explicaçăo". 
racterização das interrogações, dos modos de análise e de inteligibilidade produzidos nos parece, por sua vez, indispensável.'

\section{Principais fatos e mudanças que sustentam estas pesquisas}

Numa obra coletiva anterior (Tanguy, 1986), recordamos os fatos mais marcantes, estruturais ou conjunturais, econômicos, sociais ou políticos que sustentam as interrogações neste campo. Desde então, as pesquisas se estenderam, deslocando por vezes seus objetos de investigação em correlação com as mudanças sociais mais significativas. Dentre eles selecionaremos os que nos parecem orientar as temáticas desenvolvidas pela pesquisa, sem, no entanto, pretender dar conta das modalidades de determinação daquelas.

\section{O desemprego}

O emprego e o desemprego se tornaram o maior problema das sociedades industriais. $\mathrm{O}$ crescimento contínuo do desemprego nos últimos quinze anos é acompanhado por um conjunto de transformações sociais que constituem outras tantas questões a serem exploradas. Geral e de massas, o desemprego é um fenômeno desigual e segregativo. De um valor médio de $11,1 \%$, na França, para 0 ano de 1990 , varia de $6,9 \%$ para os homens de 25 a 49 anos a $26,5 \%$ para as mulheres de menos de 25 anos (Maruani e Reynaud, 1993). Esta discriminação ligada ao sexo é sistemática nos países europeus, excetuando o Reino Unido. A tendência ao encurtamento do tempo de atividade é particularmente forte na França onde os indices de atividade são os mais baixos para os jovens de 15 a 24 anos e para os adultos de 55 a 64 anos. Esta configuração do emprego é o produto de diferentes medidas de luta contra o desemprego, mas também de escolha de políticas educativas, de políticas empresariais e de um conjunto de ações que decorrem de valores e de crenças diferentes. Decorre daí que a população mais livre do desemprego é a que está entre os 25 e 55 anos. Inversamente, as categorias mais expostas são: os jovens com menos de 25 anos (cujo índice de desemprego é de $17 \%$ para os rapazes e de $22,6 \%$ para as moças); os menos diplomados, $14,1 \%$ contra $4,5 \%$ para os mais diplomados; e os operários, $11,8 \%$ contra $3,1 \%$ de altos empregados (Maruani et Reynaud, 1993). Todavia, cabe enfatizar que é menos o índice de desemprego dos jovens, sempre invocado nas comparações internacionais, do que o índice de atividade deles que distingue a França ${ }^{4}$ tanto dos países da Europa do norte quanto dos países da Europa do sul (Ministério do Trabalho,1993).

- Nossa apresentação se aplica essencialmente ás pesquisas realizadas na França, comparadas àquelas realizadas na Grā-Bretanha.

4 $12,2 \%$ para os jovens de 15 a 19 anos, $6,8 \%$ para as jovens da mesma idade e $62,1 \%$ para os jovens de 20 a 24 anos contra $54,2 \%$ para as jovens desta idade. Estes percentuais correspondem, na Alemanha, para o ano de 1991, respectivamente a: 40,1; 34,8; 78,6; 72,7\%. 
Ao mesmo tempo em que o assalariado toma forma generalizada, outras formas de emprego aparecem, derrogando a norma que tendia a se instituir desde os anos 50: um contrato de trabalho de duração indeterminada para uma duração semanal de 39 horas. A maioria das formas de emprego que estão em desenvolvimento rompem com esta norma do ponto de vista da duração e da estabilidade do contrato de trabalho; existem assim contratos de duraçäo determinada, estágios, empregos de tempo parcial (2,5 milhões de ativos, dos quais $85 \%$ mulheres, sobre um total de 22.233.000 trabalhadores ativos). As interpretações desta constatação divergem: são tais formas de emprego meras derrogações da norma ou as primicias de uma normalização do emprego instável? A diversificação das formas de emprego bem parece ser constitutiva de uma busca de flexibilização do mercado de trabalho; com base em semelhantes mudanças, observa-se um deslocamento do estudo das desigualdades diante do emprego e da precariedade para a análise da flexibilidade como modo de gestão de mão-de-obra.

\section{Prolongamento da escolaridade e da inserção profissional}

$\mathrm{O}$ adiamento da entrada dos jovens no mercado de trabalho é um fenômeno geral mas que reveste um caráter particularmente acentuado na França, onde o índice de atividade dos jovens conheceu a mais forte diminuição entre os países ocidentais industrializados (14,2\% entre 1979 e 1991). A relação dos jovens com o emprego não pode ser dissociada de um outro fato característico deste país: o forte desenvolvimento da escolarização. Esta conheceu uma ampliação excepcional na segunda metade da década. $O$ crescimento do índice de acesso ao baccalauréat (ver nota do tradutor) é, sem dúvida, o indicador mais eloqüente deste fato; ele passou dos $30,2 \%$, em 1985 , para $50,5 \%$, em 1992 . Assim, a quase totalidade dos jovens de 17 anos (exatamente 91,7\%), quatro quintos dos jovens de 18 anos $(79,6 \%)$ e cerca de dois terços dos que têm a idade de 19 anos (64,1\%) são escolarizados em tempo pleno," ou seja, em proporções nitidamente superiores àquelas de um país como a Grã-Bretanha. Produto de evoluções estruturais, esta propensão a um prolongamento dos estudos tem sido amplamente organizada pelas politicas educativas e de inserção dos jovens. Por isso, pode-se dizer que o acesso dos jovens ao trabalho não se efetua mais no seio e ao encargo das empresas, e sim dentro de um conjunto de dispositivos cujos quadros e modalidades de funcionamento são definidos pelo Estado, fenômeno que constitui uma das temáticas de investigação privilegiadas pelos economistas.

As diversas medidas tomadas desde o final dos anos 70 até a metade dos anos 80 , na direção de públicos considerados como apresentando caracteres comuns repousavam num postulado: como a insuficiência de qualificação era considerada a razão principal do desemprego, a formação era o instrumento exatamente recomendado para travá-lo. Mas, progressivamente, a inserção se impôs como uma categoria de pensamento e de ação distinta da formação, mesmo ficando-lhe

\footnotetext{
- Fonte: Ministério da Educação Nacional, Direçăo de Avaliação e Prospectiva.
} 
estreitamente associada (Guitton e Sibille,1992). Mais do que as formas tomadas por estas medidas de inserção e também mais do que suas variações no tempo, parece-nos ser importante sublinhar sua amplitude: os fluxos anuais de jovens beneficiados por uma ou outra destas ações passaram de aproximadamente 433.200, em 1980/81, para 1.113.359, em 1987 (Monaco, 1993) e 845.965, em 1992 (Bref, 1992, n. 73, e Ministério do Trabalho, 1993). Isto quer dizer que o fenômeno conhece uma extensão que nos obriga a analisá-lo em seus diferentes componentes. De fato, a maioria dos trabalhos realizados, notadamente pelo CEREO (Centro de Estudos e de Pesquisas sobre as Qualificaçōes), revelam que o uso de semelhantes dispositivos é uma necessidade para todos os jovens que saem da escola após o collège (ver nota do tradutor) assim como para aqueles que possuem uma formação profissional que conduz a um CAP (Certificado de Aptidão Profissional) ou a um BEP (Brevet de Estudos Profissionalizantes).' Nunca seria demais insistirmos no fato constatado, mas ainda pouco analisado, de que um mercado da formação foi criado, se por formação entendermos não apenas ações que visam à transmissão de conhecimentos gerais ou especializados (no seio de instituições de estatutos diversos, de formação inicial ou contínua) mas também um conjunto de ações de orientação (operacionalizadas por meio de dispositivos apropriados) e de integração no meio social, ou até mesmo ações de tipo psicológico junto a públicos desempregados.

A descrição assim feita da situação dos jovens no mercado de trabalho deve ser relacionada com a evolução do recrutamento nas empresas durante o mesmo período. Com efeito, recessão do emprego e inatividade ou desemprego dos jovens não estão linearmente correlacionados. Entre 1982 e 1990, o emprego dos jovens diminuiu em mais de $19 \%$, enquanto que o volume de emprego crescia cerca de $4 \%$. A parcela dos jovens no emprego foi reduzida não apenas nos ramos de atividade tais como bancos, seguradoras e comunicações, mas o foi igualmente nas atividades de comércio e do setor terciário não mercantil, que são tradicionalmente setores de inserção profissional para esta categoria da população.

No total, a diferença entre os fluxos de jovens que saem do sistema escolar e o recrutamento dos mesmos passou de 23.000 , em 1973, para 361.000 , em 1994, e 207.000, em 1989 (Bref, 1990, n.58). Por isso, em 1986, apenas um jovem em cada cinco que saíam do aparelho escolar possuia um emprego (nove meses depois), ao passo que um jovem em cada dois estava nesta situação no final dos anos 70 . A defasagem entre oferta e demanda de emprego, sabe-se, é particularmente penalizadora para os operários e os empregados, para as mulheres e, particularmente, para todos aqueles cujo nivel de formação, levada em conta a translação geral para cima e a concorrência que ela provoca, é considerado insuficiente. Afeta também os diplomados do ensino superior, cujas condições de inserção vêm se deteriorando rapidamente desde 1992 (Potier, 1993).

Todas as mudanças aqui citadas a propósito da entrada dos jovens no mercado de trabalho e de sua socializaçäo dizem respeito, na verdade, como veremos adiante, aos processos de constituição e de estratificação do próprio assalariado.

- Formações e diplomas que permitiam, num periodo anterior, ter acesso a empregos de operários e de empregados qualificados. 
Era preciso recordar estas mudanças, pois é em sua base que a pesquisa se organiza para privilegiar temáticas tais como as da inserção, das políticas educativas e de emprego, das instituições e de modos de formação, mas também aquela da comparação das formas que estes fenômenos tomaram nos diferentes países europeus.

\section{Inserção ou transição da juventude à vida adulta}

A temática da inserção profissional dos jovens é, sem dúvida alguma, a mais investida e a que deu lugar a trabalhos de estatutos diversos: descrições estatísticas, avaliações das políticas, estudos regionais, análises sociológicas de categorias de populações particulares. A abundância de literatura pode fazer crer que tal temática constitui, de algum modo, o núcleo duro de um domínio de pesquisas que afirmamos estar mal delimitado. A crise do emprego, o desenvolvimento do desemprego, as políticas de recrutamento das empresas, como acabamos de ver, constituem a origem da "centragem" nos jovens. As diversas intervenções do Estado, efetuadas na maioria dos países europeus, assim como os incentivos à sua avaliação, contribuiram, com toda evidência, para orientar o questionamento em termos de inserção dos jovens e de transição escola/trabalho (termos muitas vezes associados, embora designem abordagens diferentes de uma realidade multiforme).

"A juventude não é senão uma palavra", um conceito amplamente generalizado, segundo Bourdieu (1980). Numerosos trabalhos demonstraram que esta noção não só devia ser conjugada no plural (notadamente em termos de classes sociais e de diferenciação de sexo), mas que ela constituía também um constructo histórico e social de contornos móveis (Mauger, 1986). Esse período da vida definido por Galland (1993) como o da passagem de um estatuto etário, a adolescência, para um outro, a idade adulta, tende a se alongar: a fase da inserção profissional é mais longa e mais incerta que outrora, e as políticas de enquadramento do desemprego, anteriormente orientadas para as populaçōes com idade de 16 a 18 anos, atingem, hoje, na França, os jovens com idade de 16 a 25 anos e, em outros países, aqueles com idade ainda mais elevada. Do mesmo modo, o tempo de experimentação, das tentativas que acompanham a instalação do casal e a decisão do casamento foi, por sua vez, também alongado. O domínio das pesquisas sobre a juventude foi o objeto de um inventário sistemático, ordenado e comentado por Mauger (1993), que constitui uma ferramenta de referências extremamente preciosas e, ao mesmo tempo, um quadro que permite que nos desloquemos num universo pelo menos tão plástico e heterogêneo quanto o das relaçöes entre formação e emprego. Estas pesquisas produzem elucidações que ampliam as constataçōes feitas por aquelas centradas no acesso ao trabalho e em suas significações. É assim que os dados e as modalidades de inserção profissionais são ligados a outras mudanças intergeracionais e que as transformações do emprego são colocadas na perspectiva daquelas da produção de novas formas de hierarquização e de categorias sociais.

Estas abordagens, realizadas por sociólogos, privilegiam o estabelecimento de relações entre as diferentes situações vivenciadas pelos jovens (no mercado de 
trabalho, assim como na familia e no lazer) e o sentido dado à suas ações. Na prática, elas se referem muito freqüentemente às fraçōes mais afetadas pela precarização (Dubar et al., 1987 et Dubet, 1987), estado que, segundo alguns autores, teria a tendência de se tornar a característica da maioria dos jovens (NicoleDrancourt, 1991). Em todos os casos, são os fenômenos de socialização, de construção das identidades, e as estratégias desenvolvidas por estas populações que são colocados no centro das investigações (Galland, 1993 e Dubar, 1991).

Sob a noção de inserção, dispõem-se trabalhos mais diretamente orientados para o estudo da passagem da escola ao emprego, uma das mais vivas preocupações sociais da maioria dos países europeus. Ela dá lugar a grandes sondagens sobre a situação dos jovens nove meses após a saida deles da escola e sobre sua trajetória ao longo dos dois ou cinco anos que a seguem (CEREQ, Observatoire des entrées dans la vie adulte). As modalidades de concepção destas sondagens, os cortes que elas operam nas populações e as nomenclaturas que utilizam procedem de características nacionais que convém explicitar. Definir, contar, classificar e ordenar são operações sociais presentes em qualquer sondagem de natureza estatistica. Na Grã-Bretanha, estas sondagens se baseiam em grupos de uma idade determinada, porque a idade é o principal fator de estruturação do sistema educativo (Raffe, 1992). Com efeito, o princípio da não repetência na escola obrigatória, a ausência de diferenciação formal antes dos 16 anos, a existência de uma idade máxima para ingressar na aprendizagem ou no trabalho, o enunciado dos direitos e das garantias em termos de idades, a utilização da idade nos debates políticos e, mais comumente, a tradição de uma interrupção precoce dos estudos e a expectativa de um ingresso rápido no mundo do trabalho são fatos caracteristicos de uma estruturação pela idade (age structure). Na França, a observação se efetua de uma maneira privilegiada através dos niveis de saída do aparelho escolar por meio de nomenclaturas de níveis de formação.' Estas nomenclaturas são elaboradas não a partir das estruturas do aparelho de formação, como seu nome poderia fazer crer, mas a partir dos códigos de emprego que classificam as formaçōes ou os diplomas em função dos empregos aos quais conduzem (Affichard, 1987). Isto quer dizer que os pressupostos de uma adequação das formações aos empregos se encontram no centro de uma tal construção estatística. Segue daí que as análises feitas sobre a situação ou a trajetória das populações que saem da escola e que são classificadas por "niveis de formação" colocam invariavelmente as questões contidas na equação destas duas distribuições (a da formação e a do emprego): ocupam os indivíduos empregos para os quais foram formados e em que prazos? E se não: quem as empresas contratam? Definida no quadro da planificação para fins de previsão, tal codificação se impôs progressivamente como princípio de representação e de gestão administrativa das atividades de formação inicial ou contínua, das saídas do aparelho educativo e da inserção dos jovens. Assim, as nomenclaturas de formação, ferramentas elaboradas para fins técnicos, se impuseram progressivamente como categorias de percepção e de organização social que dirigem as políticas do Estado, das coletividades regionais ou locais e contribuem para dar forma às re-

7. O leitor interessado poderá remeter-se a Affichard (1987). 
presentaçōes que professores, famílias e alunos criam das diversas formas de ensino, dos seus lugares e das suas funçōes.

Sem poder dar conta aqui de todos os fatos estabelecidos por esses trabalhos, lembramos que eles estão na origem do conhecimento dos fenômenos maiores que caracterizam as sociedades européias: a quase exclusão dos jovens com menos formação dos empregos de contrato ordinário, a extensão dos empregos precários, a elevação do nível de formação no qual os jovens são recrutados em categoria de empregos igual, a concorrência entre os jovens de níveis de formação diferentes para o acesso a uma mesma categoria de empregos e, de forma mais geral, a especificidade de um mercado de trabalho juvenil.

As análises da inserção como processo de busca de emprego, que repousam em sondagens longitudinais, procedem geralmente por agregaçäo de caracteristícas individuais. Economistas, herdeiros da tradição neoclássica, e sociólogos, herdeiros das teorias de mobilidade social, encontram-se assim naturalmente aliados neste tipo de investigação empírica cuja eficácia salientamos. Esta maneira de agir é, entretanto, questionada por representantes destas mesmas disciplinas. É assim que, na França, Rose (1986) se empenhou em opor a noção de transição àquela de inserção, onde a primeira significa que os processos de acesso dos jovens a um emprego dependem, antes de tudo, da estruturação dos mercados de trabalho pelas políticas de mão-de-obra das empresas e pela intervenção do Estado. A transição é, então, definida como "o conjunto das formas sociais do acesso ao trabalho dos inativos" (jovens ou não), e o caráter socialmente organizado deste processo se torna primordial. Isto significa que uma tal análise privilegia o estudo dos processos de construção da oferta de formação dentro do dispositivo da inserção: oferta que se diversifica segundo as categorias de organismos (de origem patronal, associativa ou dependente do Ministério da Educação Nacional), cada qual procurando definir sua própria concepção e agir de maneira apropriada (Méhaut, Rose et al., 1987). Este tipo de análise dá ênfase à duração dos processos de inscrição no mundo assalariado, a seu caráter multidimensional, misturando situações de desemprego com periodos de atividade e de estágios de formação.

Há uma perspectiva de mercados de trabalho organizados que economistas (Marsdenet e Ryan, 1990) e sociólogos britânicos privilegiam para analisar a transição. Uns (Lee et al., 1990) focalizam suas análises nos programas de formação aplicados pelo Estado na década de 80 (Youth Training Scheme), outros (Ashton et al., 1990) se esforçam em mostrar como as práticas dos empregadores, a legislação, os acordos sindicais e as instituiçōes de formação influenciam na entrada dos jovens no mercado de trabalho e determinam suas experiências e suas mobilidades. Uns e outros atribuem maior importância aos dados provenientes das empresas, das instituições, do que àqueles que caracterizam os indivíduos. Os jovens são, assim, sempre estudados em suas relações com os adultos.

Para concluir, diremos que estas diferentes abordagens, que se desenvolvem paralelamente, obedecem a necessidades e a interesses diferentes. Todas participam de um conhecimento maior da realidade, já que elas impedem de reduzir esta

- Remetemos o leitor interessado às numerosas publicaçōes feitas na Formation-emploi, revista do CEREQ, e particularmente aos números 18 (1987) e 25 (1989). 
realidade às dimensões mais imediatamente visiveis que aparecem na cena política. Elas expressam que, se os processos de inserção dos jovens são, sem dúvida, fortemente determinados pelo desemprego, eles manifestam também transformaçōes mais abrangentes que são essencialmente, para os economistas, uma redefinição das relações salariais orientadas para a flexibilidade e a mobilidade da mãode-obra e, para os sociólogos, novas formas de estratificação social.

\section{Análise das políticas educativas e de emprego}

Pouco praticada até estes últimos anos na França, diferentemente dos paises anglo-saxões onde constitui, há muito tempo, uma tradição, a análise das políticas educativas e de emprego tende a se desenvolver em favor da institucionalização das práticas de avaliação. Ela entra, com efeito, no repertónio de ação do Estado, pela criação de instâncias permanentes ligadas, umas, diretamente ao governo e, outras, aos principais ministérios, dentre os quais o Ministério da Educação Nacional, o Ministério do Trabalho e do Emprego, e da Delegação para a Formação Profissional;' assim, entre 1989 e 1990, foram criadas não menos de sete instâncias permanentes. Segundo a interpretação adiantada por certos politicólogos (Duran e Monnier, 1992), esta institucionalização da avaliação se desenvolveria em correlação com a erosão de valores políticos anteriormente compartilhados e tendo em vista a obtenção de um acordo social. Com efeito, o presidente do Conselho Científico de Avaliação, comentando a criação desta instância, enfatiza que a avaliação é não só uma incitação a ser mais eficaz - uma vez que ela exerce sobre a administração "uma pressão análoga àquela que o mercado faz pesar sobre as empresas"- mas também um meio de levar ao conhecimento dos cidadãos as principais formas de ação pública e de colocá-los em posição de medir seu valor e sua utilidade.

Na França, a avaliação das politicas de emprego se realiza, muitas vezes, medida por medida, e não em torno dos sub-conjuntos da política de emprego. Ela tem por objetivo permitir a pilotagem dessas políticas, conhecer as populações que por elas são favorecidas, a implicação das diferentes categorias de atores presentes (administrações, empresas, formadores) e, finalmente, medir os resultados. Os critérios utilizados variam de acordo com os tipos de medidas no interior de um mesmo país, observando-se diferenças notáveis de um país para outro. É assim que, na Grã-Bretanha, o acesso ao emprego constitui o critério privilegiado de análise, ao passo que, na França, este é indissociável do acesso a uma formação e a uma qualificação. Os estudos de avaliação assim realizados produzem um conjunto de informaçōes e de conhecimentos de estatuto e de alcance diferentes. Em primeiro lugar, fornecem uma descrição indireta do funcionamento do dispositivo de inserção dos jovens. Demonstram, por exemplo, que as medidas implementadas na França sob forma de estágios tendem a se ordenar umas relativamente às outras, as primeiras servindo de filtro para as segundas que conduzem

- O decreto de 22.1.1990 institui um Comitê Interministerial de Avaliação, um Conselho Científico de Avaliaçåo e o Fundo Nacional de Desenvolvimento da Avaliação (Conselho Cientifico de Avaliaçăo, 1991). 
com uma maior probabilidade a um emprego ou a um contrato de aprendizagem. Mostram igualmente que medidas destinadas inicialmente aos públicos menos diplomados (como os contratos de qualificação) são desviadas para populações mais tituladas para fins de adaptação a funções específicas nas empresas. ${ }^{\circ}$ Por outro lado, já o dissemos e o veremos ainda mais adiante, este tipo de estudo fornece simultaneamente um conjunto de dados sobre as relações que se estabelecem entre os organismos de orientação, os organismos de formação e as empresas dentro de quadros políticos impulsionados pelo Estado; dados que constituem referências para desenvolver investigações sobre a emergência de novos fenômenos tais como os modos de formação em alternância. Dentre os resultados estabelecidos por estas avaliações, convém relembrar esta constatação universalmente estabelecida: os dispositivos não conseguem se contrapor às formas seletivas do mercado de trabalho. Além desses aportes, importa salientar também efeitos menos visíveis, mas não menos importantes, da difusão das práticas de avaliação. Estas vêm acompanhadas, com efeito, pela aplicação de dispositivos técnicos, por procedimentos de categorização, por nomenclaturas e classificações, que tendem a se impor como categorias de pensamento comuns necessárias à comunicação social e à ação. Resultam, no entanto, de um certo número de operações sociais que estão longe de ser consensuais, como vamos tentar ilustrar a respeito das políticas educativas.

As políticas educativas adotadas na segunda metade da década de 80 , na França, têm como traço mais marcante o fato de terem sido elaboradas de acordo com as preocupações do emprego e de terem sido enunciadas em termos de nível. Este deslocamento de enunciado dos objetivos de uma política educativa da ordem escolar para a ordem das qualificações, equaciona ensino, formação e qualificação; equação que oculta $\circ$ fato de que a qualificação não é uma propriedade conferida pelo sistema educativo aos individuos mas uma relação social que combina vários parâmetros e que é determinada pelo mercado de trabalho. São operações que mostram a força das crenças sociais na escola, a pregnância das classificações que ela efetua e a ocultação assim gerada. A lei de orientação de 1989 estipula efetivamente que a totalidade de uma faixa etária que sai do sistema educativo deve estar qualificada, no mínimo, no "nivel V". Ela corrige, assim, a palavra de ordem proferida quatro anos antes: " $80 \%$ de uma faixa etária no nível do baccalauréat, cujos efeitos perversos estavam então aparecendo. À luz da análise, parece que esta política continha implicitamente uma desvalonização dos modos de formação das competências classificadas no nivel $\mathrm{V}$, na medida em que ela organizava um movimento de translação geral para o nível IV, mensurado pelo baccalauréat que se tornava assim a norma. Colocar o "nível V", que corresponde aos empregos dos operários e de empregados qualificados, como nível mínimo é, com efeito, negar a especificidade da qualificação operária. De fato, o CAP, o certificado mais antigo e sempre reconhecido pelas convenções coletivas e que sanciona a qualificação operária, foi invalidado na escola e por ela. Sua manutenção, sob forma menor, parece muito diretamente ligada ao objetivo de conferir a todos os

" Os trabalhos realizados com esta orientação são, na maioria, publicados na revista do Ministério do Trabalho e do Emprego, Travail et emploi, e na revista do CEREO, Formation-emploi. 
jovens que saem da escola uma qualificação mínima. É este enunciado em termos de nível e de qualificação que fomos levados a discutir (Tanguy,1991).

Todos os fatos e contradições assim trazidos à tona só podem ser compreendidos e interpretados ao preço de investigações capazes de reconstituir os principais elos de uma longa cadeia de relações que vai desde a formulação de uma demanda pragmática e circunstanciada das empresas diferenciadas em diferentes categorias de competências até a elaboração de uma demanda mais ampla, por exemplo, ao nivel do ramo econômico, a seguir, até a definição de um demanda em escala societal e, finalmente, até a sua inscrição numa política educativa. Esta última operação, potencialmente a mais conflituosa, exige traduzir expectativas profissionais no registro dos conhecimentos cientíicos e técnicos e, simultaneamente, adotar um modelo de formação que coloque em relação estas expectativas com uma representação do futuro do desenvolvimento social. Foi por isso que a análise que conduzimos focalizou uma instância, as Comissões Profissionais Consultivas (CPC), onde se efetua a confrontação entre os meios profissionais empregadores e assalariados com o meio escolar e a administração do Estado para decidirem a respeito dos contornos e dos conteúdos dos diplomas. Desse modo, podese mostrar como as demandas em diferentes tipos de competências formuladas, explicitamente ou não, pelos meios profissionais são traduzidas em termos de niveis e de diplomas dentro de quadros fixados pela administração do Estado e caracterizar o desvio de orientação das práticas educativas para a formação de competências relacionadas com o emprego.

Isto significa dizer que, confrontado com as solicitações de avaliação das políticas públicas (ou outras) que lhe são feitas, o pesquisador é levado a problematizar esta solicitação, a interrogar-se sobre as escolhas feitas na elaboração das políticas e a elaborar os postulados subjacentes às mesmas (Guittone Sibille, 1992).

\section{Instituições e modos de formação}

A abordagem das instituições e dos modos de formação, amplamente desenvolvida pelos sociólogos da educação, permanece neste domínio de pesquisas menos freqüente do que nos anteriores. Ela dirige as pesquisas que, em matéria de formação continua (ver Tanguy, 1986), visam a identificar as organizações que têm como função traduzir as demandas das empresas diferenciadas numa demanda mais geral dentro de ramos de atividades econômicas (ou em outros ramos) e responder a elas segundo modalidades adaptadas às suas características (porte, organização, etc.). Não diremos nada a respeito destes trabalhos porque eles fazem parte do corpus de pesquisas examinado por Maroy no presente tratado. Examinaremos aqui os estudos que dizem respeito aos modos de formação destinados aos jovens escolarizados ou àqueles que saíram da escola e que estão à procura de emprego. Uma das mudanças maiores ocorridas neste nível parece ser claramente a aplicação de um conjunto de práticas diversas, mas todas designadas com o nome de alternância." Este termo indica um traço comum às práticas

" Os principais trabalhos realizados sobre esta temática săo o objeto de uma bibliografia comentada (Délégation à la formation professionnelle, 1992). 
progressivamente instituídas ao longo dos últimos quinze anos: a busca de uma cooperação entre as instituiçỏes de formação (escola ou organismos especializados que possuem estatutos diversos, públicos ou privados) e as empresas. Tal ação conjugada com duas instâncias sociais, por sua vez separadas, é afirmada como um princípio que dirige tanto a redefinição dos modos de formação realizados na escola quanto a organização daqueles incluídos no dispositivo de inserção dos jovens (com o qual "a formação em alternância" é, algumas vezes, abusivamente identificada). Proclamado com aquela ênfase característica das sociedades modernas, o princípio não é tão novo como se afirma. As análises sócio-históricas conduzidas por Briand e Chapoulie (1989) são a este respeito muito instrutivas. Recordaremos que os estatutos dos Centros de Aprendizagem do Pós-guerra (instituição escolar que está na origem dos Lycées professionnels - escolas secundárias profissionalizantes - na França) continham a possibilidade de convenções com as instâncias profissionais patronais e com as coletividades locais, convençōes que podem ser consideradas uma forma de alternância prefigurada (Tanguy, 1989). Este regime de convençōes, fundado numa participação das organizações de empregadores para o financiamento da formação instituía uma partilha do poder que autorizava o mundo profissional a participar da elaboração das normas, a orientar a oferta de formação e a controlar seu desenvolvimento e sua conformidade. Mas, apesar das intervençōes repetidas do Estado e do apoio das organizaçōes profissionais patronais ao longo de todos esses anos do pós-guerra, os regimes de convenções não tiveram a evolução esperada e permaneceram como formas menores até a lei de 1971 que os modifica para aplicá-los quase exclusivamente à aprendizagem na empresa, enquanto que a forma escolar se tornava, sob a ação de forças sociais conjugadas, a forma prevalente. Exceções existem, tal como um organismo de formação paritária no setor da construção civil e de obras públicas, onde se mantém uma tradição de ofício.

A ingerência das empresas no processo de formação recuou, portanto, ao longo das décadas de 60 e 70 em correlação com a extensão da escolarização. É por isso que a aproximação entre empresas e escolas, considerada uma das mudanças mais significativas ocorridas no sistema escolar francês, é representada e percebida sob o ângulo da novidade: aproximação que se realiza sob a iniciativa do Estado. De maneira mais geral, parece-nos possivel dizer que as tentativas de aproximação escola/produção são impulsionadas por organismos internacionais, Como OCDE, e pela CEE (Cortese, 1992, e Réa, 1992). Poderiamos igualmente mostrar que as instâncias européias constituem a fonte da idéia de uma melhoria da formação profissional por alternância, lançada já na metade da década de 60 . Adotado hoje pela maioria dos paises europeus e elaborado pelas autoridade politicas sob formas variadas (OCDE, 1992), o princípio encontra sua forma completa e sua representação ideal no sistema dual alemāo.

Os trabalhos realizados sobre estas questões, que sâo essencialmente descritivos, fazem surgir a necessidade de distinguir as acepções e modalidades de aplicação do princípio da alternância de acordo com os lugares e os públicos aos quais se destina, segundo as categorias de agentes implicados e segundo os fins buscados. A aproximação escolas/empresas, designada pelo termo alternância se 
dá sob formas diversas: desenvolvimento de estágios para os alunos que preparam uma formação profissionalizante destinada aos empregos de operários e de empregados; integração na empresa em periodos variando de 12 a 24 semanas, por dois anos, em cursos de formação recentemente criados - como o que conduzia ao baccalauréat profissionalizante em 1986 - que são apresentados como figuras simbólicas da cooperação buscada; criação de cursos profissionalizantes no ensino superior tais como maîtrises (ver nota do tradutor) em ciências e técnicas aplicadas, com obrigação de estágios em empresas - a maioria dos jovens que se preparam para a obtenção de um diploma (brevet) de técnico superior (BTS) ou de um diploma universitário de tecnologia (DUT) fazem um tal estágio. Poderiamos acrescentar a criação de sistemas de integração empresa/escola (1985), a instalação de instâncias tais como o Alto Comitê Educação-Economia (1986) que tem como função explícita estabelecer um acordo permanente do mais alto nivel entre a Educação Nacional e os parceiros econômicos. Todas estas formas de colaboração, decididas em escala central, se realizam no quadro de convenções negociadas em escala local pelos parceiros imediatos - na maioria das vezes, a empresa e o estabelecimento escolar específico - que entram em relação com base num relacionamento recíproco.

Das observações feitas conclui-se que a redefinição do processo de formação assim realizada não coloca em questão, no entanto, o papel central da instituição escolar. Se as empresas aparecem cada vez mais como locais de formação, elas estão longe de poderem ser consideradas agentes de formação aptos a definir as normas. Sua ação fica circunscrita nos quadros definidos em termos de tempos e de ações pelas convençðes, pelo menos em negativo: é o caso das tarefas a serem atribuídas aos alunos e das experiências que eles devem adquirir no quadro da preparação para um baccalauréat profissionalizante.

A alternância aplicada no dispositivo de inserção profissional é de outra natureza; não é inútil lembrar que ele depende da tutela do Ministério do Trabalho e que ele se inscreve no quadro jurídico e administrativo da formação contínua." Esse dispositivo pode ser definido como um conjunto de arranjos institucionais eminentemente instáveis; as formas sucessivas que revestiu são uma ilustração eloqüente disso (Monaco, 1993).

Todavia, todos repousam na idéia de um estágio na empresa associado a uma formação dentro de um organismo habilitado. Assim descrita, esta forma de alternância é a imagem invertida da anterior, já que ela repousa na primazia atribuída à empresa. Na verdade, as funçð̌es atribuidas a uma ou outra instância não são, neste caso, praticamente explicitadas e não são, a fortion, objeto de regulamentação. As normas que regem os estágios nas empresas e as açōes de formação nos organismos continuam fracas, limitando-se, no melhor dos casos, em fixar o tempo

12 Inicialmente destinado aos jovens que saíam da escola sem terem alcançado o nível escolar socialmente exigido - noção mal definida mas que pode ser estimada através do êxito no primeiro ciclo do ensino secundário (collége) - este dispositivo foí estendido, em seguida, aos jovens dotados de uma formação profissional que conduz aos empregos de operários e de empregados (CAP e $B E P$ ), depois a todos os jovens de 18 a 24 anos à procura de um emprego. 
atribuido às aprendizagens fora das situaçōes de trabalho. A implantação da alternância é aqui justificada como uma via de acesso ao emprego ou à qualificação.

Estes movimentos de transformação são o objeto de pesquisas que podem, ao preço de uma certa redução, ser classificadas segundo a predominância de sua orientação. Trabalhos que qualificaremos como de inspiração pedagógica visam a analisar as mudanças assim introduzidas em matéria de transmissão e de aquisição dos conhecimentos, de divisão de tarefas na produção das competências e de emergência de novos atores tais como instrutores e tutores nas empresas (Aghulon, 1992, e Delegação para a Formação Profissional, 1992). A maioria destes trabalhos dizem respeito à alternância instituída no quadro das instituições escolares. Outros privilegiam a análise dos processos de socialização em vias de desenvolvimento com estes novos modos de formação para tentar identificar os tipos de comportamentos, de atitudes e de representações que aí são transmitidos e adquiridos. Tais análises tendem a mostrar que as formas de aprendizagem das condições sociais do trabalho assalariado, que ficaram progressivamente enfraquecidas na escola, são transferidas para a empresa (Tanguy, 1991 a; Delegação para a Formação Profissional, 1992; Monaco, 1993). Enfim, um terceiro conjunto de pesquisas de orientação sócio-econômica, aplicadas quase exclusivamente ao dispositivo de inserção, o analisam e o interpretam como uma modalidade de gestão do desemprego que participa da categorização da mão-de-obra e da sua situação precária. Em termos gerais, estes autores enfatizam que a institucionalização das formações em alternância não poderia ser reduzida à divisão entre escolas e empresas - e ainda menos aos fenômenos precedentes que lhe são inerentes - mas deve ser analisada em termos mais gerais de mobilização e de gestão da mão-de-obra (Rose, 1992 e Monaco, 1993).

Além das diferenças de interpretação destacadas para dar conta de tais mudanças, um certo número de fatos parece bem estabelecido. Antes de tudo, o recurso generalizado ao princípio de alternância entre escolas ou organismos de formação e empresas se realiza sob formas específicas e irredutiveis umas às outras, segundo um público de jovens escolarizados ou em busca de emprego. Em último caso, há concordância sobre este menor denominador comum para ver em ação, em tais modos de formação, processos de socialização, constatação que deixa aberta a análise destes últimos. Ademais, parece que, longe de ser um fenômeno generalizado, a ingerência das empresas nestes processos surge, ao contrário, como 0 fato de categorias bem determinadas, essencialmente as pequenas e médias empresas, em setores limitados, como a construção civil, o comércio varejista, os serviços mercantis, a hotelaria, o conserto e o comércio de automóveis. As observações convergem igualmente para expressar que as fronteiras entre trabalho, desemprego e formação se diluem e confundem as percepções que os jovens têm de suas situações. De fato, o caminho entre a escola e o emprego não só se alongou mas também se organizou pela ação de instâncias de estatutos diferentes, que vão das instituições de orientação a organismos de formação privados, públicos, associativos - e às empresas. Assim se desenha e se estende um domínio de atividades socialmente denominado "formação" que designa um conjunto de práticas heterogêneas realizadas por categorias de agentes diferentes: 
conselheiros de orientação, formadores que adquirem estatutos variados ao término de itinerários diversificados, tutores de empresas cujo arquétipo é o orientador de estágio. São aspectos que exprimem, para além de sua diversidade, a ampliação de um domínio de atividades sociais onde a empresa tende a se firmar como lugar e agente da formação entendida no seu sentido amplo.

Simultaneamente e em estreita dependência com os movimentos descritos, as ações negociadas entre o Estado e os parceiros sociais se estendem. Tradicionalmente aplicadas aos assalariados ativos ou desempregados, estas ações negociadas englobam, a partir de então, a massa dos jovens desempregados, enquanto que professores, Estado e empresas definem as convenções que dirigem a colocação dos jovens escolarizados nos locais de trabalho. Isto revela que o princípio da alternância se inscreveu progressivamente nos fatos e se impôs mesmo àqueles que o contestaram duramente, especialmente os sindicatos de docentes. Mas, se há um certo entendimento social sobre este princípio, seu uso continua sendo eminentemente discutido.

\section{Qualificações, competências}

O caráter central que a noção de qualificação reveste na França lhe é conferido pelo fato de ela fundamentar um conjunto de práticas que visam a relacionar 0 funcionamento do sistema educativo e do sistema produtivo. Assim compreendida, esta noção vai conduzir, logo após a segunda guerra mundial, diversas medidas institucionais, dentre as quais as grades de classificação que repousam num compromisso social ao termo do qual são definidos os princípios de relação de duas distribuições hierarquizadas, a dos individuos segundo suas capacidades e a dos empregos aos quais são atribuídas remuneraçōes. Mais especificamente, as grades de classificação definem as regras que determinam as principais fases da troca do trabalho, ou seja, concretamente, o recrutamento dos assalariados, sua atribuição a um posto de trabalho, sua remuneração e sua promoção. Um tal trabalho de formalização e de codificação se realiza geralmente na escala dos ramos profissionais, lugar de organização privilegiado pelos empregadores e pelos assalariados na medida em que eles têm acesso assim à ação política e social. É ainda a noção de qualificação que está no centro das práticas de planificação desenvolvidas no decorrer dos anos 60 , até a metade dos anos 70 , momento em que a busca de um adequação entre a formação e o emprego por meio de um ajuste dos fluxos de escolarização às previsões em categorias de mão-de-obra é abandonada (Bel, 1986). Abandonada enquanto objetivo a ser alcançado, em escala nacional, esta idéia alimenta ainda certos debates em escala regional especialmente.

Em suma, a fecundidade da noção está inscrita no seu estatuto: uma categoria da prática social que relaciona duas grandes ordens de fenômenos histórica e institucionalmente distintos (Tortajada, 1986). $O$ uso desta categoria não levanta maiores problemas em periodo de crescimento econômico, onde a questăo da escassez de mão-de-obra qualificada domina. Mas, a partir do momento em que 0 desemprego aparece como o problema social prioritário a ser resolvido, a noção é questionada em seus fundamentos e em sua pertinência. $O$ que gerava acordo se torna objeto de desacordo. A unanimidade em torno da idéia de uma necessária 
extensão da formação dá lugar à oposição de pontos de vista a respeito do sentido a ser dado ao que se denomina qualificação. $O$ ponto de vista comum sobre um dado natural é pulverizado.

Além do lugar ocupado e das funções preenchidas por esta noção, é importante lembrar que ela constitui o objeto de debates teóricos que CampinosDubernet e Marry (1986) reconstituiram, opondo uma abordagem substancialista encarnada por Friedmann (1973 e 1956) e uma abordagem relativista e conflituosa representada por Naville (1956 e 1963). Uma vez que os termos do debate são incessantemente rejeitados, dando lugar à repetição de questionamentos sem

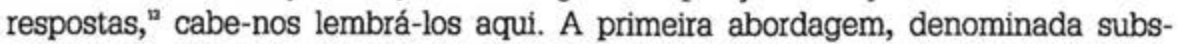
tancialista, identifica a qualificação do trabalho à sua complexidade, ou seja, em última análise, à importância da atividade intelectual que ele requer. Ela postula: "[...]a possibilidade de comparar, de medir numa escala única (a partir de um indicador desta complexidade do trabalho - na maioria das vezes a formaçăo), as diferentes qualidades da força de trabalho, num momento dado e também no decorrer da História: para tanto, ela coloca a hipótese de uma correspondência estreita entre o grau de complexidade de um conjunto de tarefas e as aptidões ou competências manifestadas pelos trabalhadores na execução destas tarefas. A qualificação coincide então com a estrutura da divisão do trabalho, a qual depende essencialmente da tecnologia utilizada ou das relaçōes capitalistas" (CampinosDubernet e Marry, 1986). Paradoxalmente, esta concepção, que se desenvolveu a partir de uma reflexão geral sobre os efeitos do desenvolvimento técnico sobre o trabalho humano - em termos de conteúdo das tarefas, de formas de remuneração, de atitudes e de ações dos operários da grande indústria - estabelece suas observações e seus princípios de explicação num espaço bem circunscrito, a oficina.

Em contrapartida, as abordagens relativistas, cujo precursor pode ser considerado Naville, definem brevemente a qualificação como uma relação social cujos termos variam no tempo e são o produto de uma relação de forças e de conflitos. Estes podem ser observados nas negociações profissionais entre empregadores e assalariados nas grades de classificação. Se Naville, neste ponto distinguindo-se da maioria dos sociólogos, considera que o desafio da qualificação continua sendo o salário, ele se esforçou constantemente para mostrar o caráter relativo e contraditório desta relação social que resulta das diferentes operações realizadas para classificar, hierarquizar os indivíduos e os empregos em termos de salário, mas também de pretígio e de conhecimentos exigidos. Fica sublinhada assim a necessidade de evitar o obstáculo de uma definição substancialista que postula que a qualificação pode ser reduzida a uma única dimensão, as propriedades intrínsecas aos indivíduos, suas competências, habilidades ou saber-fazer. Esta concepção da qualificação dirigiu os trabalhos de sociólogos como Rolle e Tripier (1978), preocupados em sair do círculo fechado da empresa a fim de observar as estratégias desenvolvidas pelas diferentes categorias sociais de assalariados e de empregados para trocar trabalho e preço; ela orienta igualmente a análise de Alaluf que se

v Dentre estes questionamentos, citaremos aqueles lançados em termos de desqualificação/superqualificaçāo (Freyssenet, 1974 e Braverman, 1976) e, hoje, em termos de competências opostas à qualificação. 
empenha em mostrar que "se a qualificação é determinada fora do trabalho, em particular no quadro do sistema escolar, ela só pode se manifestar e ser sancionada em relação ao trabalho" (1986).

As pesquisas continuaram a se desenvolver neste campo, mas praticamente não se renovaram; no máximo, estenderam-se a categorias sociais até então quase ignoradas pela sociologia do trabalho, como os professores e os policiais (Sociologie du Travail, 1987). Os trabalhos conduzidos pelos especialistas das relações profissionais que se empenham, em suas análises da classificação, em mostrar que a qualificação não é dissociável dos processos sociais que a constroem, das operações de classificação e de hierarquização dos empregos que a codificam (Eyraud et al., 1989) constituem exceção. De outro lado, um grande número de sociólogos se interessa hoje pela valorização das qualidades dos trabalhadores, valorização que estaria ligada a organizações do trabalho cujas virtudes qualificantes são colocadas em evidência. Fazendo isso, eles dão enfoque a certas dimensões da realidade que eram, segundo eles, antes subestimadas, para finalmente projetar uma imagem invertida do mesmo fenômeno. É assim que à desqualificação, dita consecutiva ao desenvolvimento técnico, segue uma valorização das competências dos trabalhadores, por sua vez, também exigida pelas mudanças técnicas (trabalhos que Maroy trata nesta obra). A noção de competência e aquelas que estão associadas a ela - saber, "saber-fazer" - como o demonstrou Stroobants (1991), tendem se não a rejeitar a noção de qualificação, pelo menos, a limitar seu alcance. Servindo-se dela sem questionamento prévio, os pesquisadores contribuem para sua difusão mais do que para sua análise. Na verdade, o conteúdo da noção de competência permanece fluido: ele emana do senso comum ou de esferas científicas como as ciências cognitivas ou a lingüística. Portanto, propusemo-nos, juntamente com outros (Ropé e Tanguy, 1993" tar elucidar os tipos de mudanças que ela designa, e isto nas duas esferas de atividades sociais distintas que são a educação e o trabalho. Efetivamente, se todo o mundo está de acordo em reconhecer que a competência se situa entre conhecimento e situação, conclui-se que sua identificação se reduz, na maioria das vezes, seja a uma classificação dos conhecimentos, seja a uma tipologia das situações que remetem a descrições de atividades (Merchiers e Pharo, 1992).

Pudemos assim mostrar que a noçăo de competência adquire um estatuto relativamente central no sistema educativo francês, com relação à redefinição dos conteúdos de ensino no final da década de 80 . Ao longo desta, foi elaborado um conjunto de princípios que organizam e legitimam a passagem de um ensino centrado no saber disciplinar a um ensino definido por competências verificáveis em situações e tarefas específicas e que visa produzi-las. Esse movimento de redefinição de um modelo pedagógico mobiliza um conjunto de métodos, de procedimentos e de noções que se aplicam a todas as ordens e ciclos de ensino sob formas diferentes. Entretanto, a configuração das noções organizadoras deste modelo pedagógico - objetivos, competências, saber, "saber-fazer", projeto, contrato encontra sua completa expressão no ensino técnico e profissionalizante onde a

" A publicação dessa obra está prevista para este ano, 1997, pela Editora Papirus/SP (nota da rev. técnica). 
centragem nas aprendizagens e em sua avaliação em determinadas tarefas não é disputada por força de uma tradição centrada na transmissão de um patrimônio cultural.

Todas estas transformações são justificadas pela idéia de racionalização reivindicada pelos diferentes protagonistas que estão em sua origem e que vão das autoridades políticas aos construtores de referenciais, passando pelos cientistas convocados para dar legitimidade aos movimentos impulsionados. Não se pode ignorar que uma pedagogia fundada nos objetivos e nas competências parece particularmente adaptada às novas exigências sociais de avaliação - entre as quais aquelas da avaliação das aquisições dos alunos, prática invocada por toda parte na década de 80 e que exige a execução de procedimentos de padronização e de técnicas fundadas na medida.

Um movimento paralelo é observado nas empresas com as práticas de codificação do trabalho em termos de competências. Estas práticas exigem romper com os modos preexistentes de designação ao trabalho, de promoção e de remuneração, tais como aqueles difundidos com o nome de job evaluation. Elas avançam, com efeito, o princípio de uma remuneração ligada aos saberes e às habilidades possuídos pelos indivíduos, e não àqueles que são exigidos pelos postos de trabalho. Sem poder dar aqui uma visão da execução destas idéias, diremos que elas emanam especialmente das grandes empresas ${ }^{16}$ e observaremos que elas constituem 0 objeto de um conjunto de operações sociais que lhes dão forma e legitimidade. $\mathrm{O}$ conjunto dos fenômenos até então não considerados em si mesmos e hoje denominados competências chegam ao seu reconhecimento social por meio de técnicas de objetivação e de medidas, dentre as quais aquelas que visam à avaliação das competências exigidas pelos empregos e, sobretudo, das competências possuidas e adquiridas pelos assalariados. Assim se desenvolve um conjunto de instrumentos de procedimentos e de categorizações, tais como aqueles de "saberfazer", "saber-ser" cuja posse se mede em termos de ser capaz; termos que, acrescentados a outros - como saberes declarativos e procedurais, algoritmos, heurísticas, competências tácitas, capacidades de resolução de problemas, cognição - atestam um empréstimo das ciências da cognição. Empréstimo que, como enfatiza Stroobants (1993), substitui pouco a pouco o retrato do operador especialista àquele do trabalhador. Efetuado sem discernimento, este empréstimo gera muitas confusōes acerca da transferência das capacidades de um domínio para um outro, objetivo hoje buscado (tanto na escola como na empresa) para facilitar a mobilidade e a adaptabilidade dos indivíduos. Todavia, as ciências cognitivas não fornecem tais modelos, mas antes demonstram que, se a transferência para situações vizinhas de um mesmo domínio é possível, a transferência para outros dominios ou para outras disciplinas é, por sua vez, quase impossivel.

Para concluir, diremos que, se as semelhanças de mudanças ligadas ao uso do termo competências na esfera educativa e na esfera do trabalho não podem ser

15 Na França, o acordo CAP 2000, assinado em 1990, entre o grupo das empresas siderúrgicas e mineiras (GESIM) de um lado e as organizaçóes sindicais de assalariados de outro - com exceção da CGT - conhecido pelo nome emblemático de lógica de competências, é figura de referência no mundo das empresas. 
analisadas dentro de um mesmo esquema de inteligibilidade, que negaria suas especificidades respectivas, não é menos verdade que um certo número de homologias devem ser observadas: uma mesma centragem nos indivíduos, colocados no centro das organizações escolares ou produtivas, e em seus atributos cognitivos, um mesmo recurso a procedimentos de racionalização, de formalização técnica e de medida para transmitir e avaliar estes atributos. Práticas que são todas legitimadas por uma busca de eqüidade e de consentimento que estariam fundadas na objetivação e na incorporação de regras formalizadas.

Enfim, não poderiamos ocultar que estas técnicas se aplicam em fixar as modalidades de recrutamento, de promoção e de remuneração, ou seja, aplicações que conduzem a determinação das relações salariais na empresa. Com efeito, as práticas de avaliação e de validação das competências tendem a colocar em questão as formas codificadas coletivamente a partir dos diplomas e da antigüidade. Tudo se passa como se a competência, um conjunto de propriedades instáveis que devem constantemente ser submetidas à prova, se opusesse à qualificação mensurada, em grande parte ao longo deste último período, pela antigüidade e pelo diploma, título adquirido de uma vez por todas.

Ademais, a analogia que existe entre as técnicas, as categorizações realizadas nas empresas a fim de identificar e de avaliar as competências e aquelas utilizadas na instituição escolar para definir os saberes a serem transmitidos e avaliar sua aquisição deve ser enfatizada ao nosso ver. Estas analogias de formas, se nâo forem de conteúdos, e a configuração de noções associadas àquelas de competências, em duas instâncias além de tudo socialmente distantes, como aquela de contrato, de objetivos, de percurso, de métodos de avaliação, todas associadas à aplicação de instrumentos de medida, atestam efetivamente a mesma representação de individuos, atores racionais dotados de consciências calculadoras. Tanto num como no outro caso, prevalece a mesma visão intelectualista da ação humana fundada em intençöes racionais.

Certamente, não seria demais insistir nisso, estas homologias são o resultado de processos e de cadeias de relações muito diferentes: devem, por isso, constituir o objeto de estudos empíricos que ressaltarão as especificidades respectivas. Contudo, parece-nos fundamental não perder de vista o "paralelismo das transformaçōes sociais", pois uma das tarefas das ciências sociais, segundo Élias (1991), consiste em evidenciar "a orientação comum a todas as transformações das relaçōes humanas, não apenas numa esfera particular mas em todas as esferas", embora não se disponha sempre das ferramentas conceituais necessárias "para poder expressar claramente em que consiste a transformação global da sociedade e, portanto, a relação entre esses diferentes aspectos". Quando muito, pode-se avançar a idéia de que as noçōes e os instrumentos técnicos em uso nas instituições de formação e nas empresas são produzidos por um meio profissional que precisaria ser identificado em seus diferentes componentes. A este respeito, as redes de interações entre homens de empresa e homens da Educação Nacional devem ser consideradas, uma vez que autorizam convergências de representações e de quadros de pensamento subjacentes a uma formalização social e técnica em termos de competências. 
A argumentação apresentada aqui se aplica à realidade francesa, mas podemos observar que um movimento semelhante ocorre na Grã-Bretenha onde a noção de competência substitui a de skills, deslize semântico que expressa também aí uma mudança de configuraçōes das relações entre a formação e o trabalho (Rainbird, 1994). A aprendizagem e ao reconhecimento das capacidades adquiridas no local de trabalho sucede uma definição normalizada e um certificado nacional das mesmas (Jessup, 1991). Esta mudança de lugar, de modalidades e de instâncias de decisão contém a mesma propensão, assinalada anteriormente, em dissociar os salários dos postos de trabalho para ligá-los às competências validadas dos trabalhadores (Ryan, 1993). Dito de outra forma, observa-se um mesmo movimento em contextos nacionais diferentes. Em ambos os casos, ele abala configurações existentes: na França, a tradição "qualificação/classificação" negociada em escala nacional (setorial); na Grã-Bretanha, uma tradição de capacidades (Skills) ligadas às profissōes, amplamente negociadas em escala de oficina. Em ambos os caso, estas mudanças surgem num momento em que o sindicalismo está enfraquecido e a flexibilidade do emprego é o objetivo buscado. 0 que vale dizer que em ambas as situações estes movimentos acontecem sem que os atores envolvidos (principalmente os sindicatos dos assalariados) tenham definido um campo de ação comum.

\section{Comparações internacionais}

O método comparativo, hoje freqüentemente utilizado por políticos, jornalistas e especialistas de todos os gêneros, não está em seu começo. Durkheim não considerava a comparação o instrumento por excelência da pesquisa em Sociologia por ser dotada de virtudes demonstrativas? Mas para ser realmente demonstrativo, este método deve ser praticado com rigor, lidar não com variações isoladas e sim com séries de variações e, como ensinou Dumézil (1958 e 1981), eminente comparatista, tratar não fatos isolados mas estruturas, ou seja, relações entre um conjunto de fatos. É exatamente o que faz a análise societal apresentada por pesquisadores do LEST (Maurice, Sellier e Silvestre, 1982) e que fez época. Ela se dedica a comparar, com efeito, não fenômenos particulares e sim conjuntos de fenômenos interdependentes que constituem coerências nacionais próprias a cada país, ou seja, a dar conta das configurações nacionais da relação salarial. Para isso, os autores retêm três grandes registros de fatos: os fatos educativos - produção e valorização dos diplomas na escola e na empresa; os fatos organizacionais - divisão das tarefas e dos modos de cooperação entre as categorias de assalariados das empresas; fatos característicos do sistema de relações profissionais - regras a respeito das remunerações, dos conflitos e da mobilidade. Nesta perspectiva, os modos (ou sistemas) de formação, por conseguinte, só podem ser comparados se relacionados com os espaços sociais que lhes dão sentido: a organização do trabalho, as relações profissionais, a mobilidade social. Os autores resgatam assim dos "espaços de qualificação" conjuntos construídos pelos atores e pelas instituições, que apresentam características especificas em cada um dos países. 0 espaço de qualificação alemão se caracterizaria por uma certa continuidade entre o operário qualificado, o técnico e, pelo menos numa época anterior, o engenheiro 
graduado, que possuem em comum o certificado de aprendizagem prática. Ele se oporia ao espaço organizacional francês que repousa numa forte hierarquia de postos, numa descontinuidade não menos forte entre empregos de execução e de concepção, numa preferência social por um ensino geral e numa desvalorização das formações profissionais. Tal maneira de proceder permite pensar em conjunto os grandes traços característicos do sistema de formação e do sistema produtivo em um país e evitar as interpretaçōes em termos de disfunçōes, de desajustes ou de inadequação entre os títulos escolares e seus usos, entre os conteúdos de formação e os conteúdos de trabalho.

Este método abriu espaço para inúmeras exegeses e debates, dos quais reteremos somente as formulações recentes feitas pelos próprios autores, em 1989 e em 1991, por ocasião de um debate com D'Iribane sobre as virtudes e os limites respectivos da análise societal e da análise culturalista. Ele inspirou também inúmeros trabalhos que, para segui-lo, visavam também a modificar sua orientação, corrigi-lo e até mesmo questioná-lo.

Entre estes trabalhos, citaremos a pesquisa dirigida por Campinos-Dubernet $\mathrm{e}$ Grando (1988 e 1989) que nos parece ser uma boa ilustração da análise comparativa aplicada a um setor de atividades econômicas, o BTP (setor econômico da construção civil e de obras públicas), em quatro paises europeus (Alemanha, Inglaterra, Itália e França), e onde os fatos de formação são considerados num conjunto de relações." Para esses autores, a inteligibilidade de um sistema de formação só pode ser apreendida em sua articulação com a estrutura do assalariado. É por isso que eles estabelecem uma comparação dos modos de formação profissional no setor BTP a partir das relações que estes modos de formação mantêm com o sistema educativo em seu conjunto, com o mercado de trabalho, a partir do lugar do setor no conjunto das atividades econômicas e, de maneira mais geral, do tipo de regulagem ou de gestão ao qual obedece (profissional ou estatal).

Em oposição à opinião segundo a qual a distinção dos espaços onde se efetua a formação profissional seria o fator determinante que confere a esta seus traços essenciais, Campinos-Duvernet e Grando nos demonstram que isso é diferente, pois, a despeito das aparências, o sistema dual alemão e a formação profissional escolar na França apresentariam mais semelhanças entre si do que o sistema dual e a aprendizagem na Grã-Bretanha apresentam. Para os autores, o que é determinante é a existência de um conjunto relativamente extenso de normas que regulamentam a formação profissional em seus diferentes elementos constitutivos: duração, espaço, conteúdos, controle das aquisições.

A distinção assim estabelecida entre os dois modelos pode ser interpretada, a nosso ver, em termos da autonomia que os sistemas de formação tenham ou não adquirido na história. Existe autonomia de um sistema de formação em relação ao mundo econômico - o que não significa ausência de ligação com ele - quando a sociedade passa a ser dotada de um conjunto de instâncias especializadas que dispōem da capacidade de recompor as demandas particulares de formação numa demanda social geral; autonomia que pode revestir formas diferentes. Assim, em-

* O exemplo dos bancos e companhias de seguros, estudado por Moebus e Verdier (1992), é também instrutivo. 
bora o sistema dual seja amplamente construido sobre a demanda espontânea das empresas, esta é transposta numa demanda social maior por intermédio de múltiplas instituições e agentes especializados que pertencem uns à esfera do Estado e outros à esfera profissional. A autonomização do sistema dual, que se enraíza no mundo profissional, difere, portanto, notavelmente da autonomia que o sistema de formação adquiriu na França ao integrar-se no aparelho escolar.

Este tipo de pesquisa possui o mérito de invalidar os questionamentos em termos de alternativas tais como escola ou empresa, formação geral ou especializada, mostrando que, por serem confrontadas com os mesmos problemas, as sociedades européias são levadas a elaborar respostas a partir de um conjunto de determinantes inscritos em suas estruturas a fim de produzir a mudança esperada. Sendo assim, os esquemas de análise propostos aqui nos alertam contra uma tendência muito disseminada de aderir aos modelos de causalidade linear e a uma concepção do tempo que o leva a uma progressão contínua. Estes esquemas derrubam também uma idéia solidamente ancorada na opinião segundo a qual a capacidade de um sistema de formação dependeria, antes de tudo, de sua ligação direta com o sistema produtivo. Ora, parece que os modos de formação profissional que dispunham da menor autonomia - por serem estreitamente dependentes do mercado de trabalho - não tiveram a capacidade de resistir às mudanças impulsionadas pela organização do trabalho, ao passo que aqueles que dispunham de uma maior autonomia tiveram a capacidade de traduzir as novas demandas que lhes eram dirigidas em sua própria lógica para trazer a elas respostas gerais, integradas num projeto social aberto para o futuro.

A análise proposta por Géhin e Méhaut (1993) se inscreve explicitamente na linha da abordagem teórica desenvolvida pelo LEST, mas dela se distingue por pretender situá-la numa perspectiva dinâmica e deslocar a análise da busca das coerências da relação salarial nos diferentes países para os níveis intermediários a fim de tornar visivel o que se chama "a segmentação interna à aprendizagem" (segundo as profissões, o porte das empresas) que era amplamente subestimada (apesar de ter sido mostrada desde o início da década por Tanguy e Kieffer, 1982) e que, por isso, ocultava a questâo dos não qualificados. De início, os autores afirmam sua intenção: é preciso romper com a representação unidimensional que é feita do sistema escolar francês, reduzido às formas escolares, ao passo que este pais constituiu, desde 1971, um aparelho de formação contínua que se desenvolveu muito ao longo das duas últimas décadas (Verdier, 1989) e, essencialmente, sob a tutela das empresas, tanto e de tal forma que a crítica emitida sobre o caráter escolar e estatal do sistema de formação ignora este fato não menos significativo que é a forte ingerência das empresas francesas na formaçăo contínua. Inversamente, se o sistema de formação profissional inicial alemão se construiu na empresa e sob a iniciativa organizada do mundo profissional, a formação contínua permanece, por sua vez, quanto ao essencial, o atributo dos indivíduos e do poder público. Géhin e Méhaut procedem à comparação destas diferenciações internas aos dois sistemas de formação, considerando-os como produtos de histórias e de estratégias de atores confrontados com exigências diferentes. 
Deslocar a análise sobre a formação contínua, mesmo considerando a relação entre formação inicial e formação contínua, vai permitir aos autores colocar em questão um certo número de proposições estabelecidas por Maurice, Sellier e Silvestre sobre o espaço de qualificação. Bem como estes últimos, Géhin e Méhaut combinam fatos observados em microescala, a partir de estudos feitos em empresas (da química, da telefonia e da mecânica) e de dados estatísticos e institucionais. Eles destacam as dificuldades da comparação traçada por eles e que se devem à própria natureza dos fenômenos estudados e aos tipos de designação social dos quais eles são o objeto. É porque a noção de formação não designa a mesma coisa na França e na Alemanha. Na França, as ações de formação são mais facilmente identificáveis porque na maior parte externas ao ato de trabalho, ao passo que, na Alemanha, os processos de transmissão dos saberes e das habilidades são mais dificilmente separáveis da organização do trabalho, devido à pregnância da aprendizagem e das funções de formador explicitamente atribuidas à mestria que autorizam a existência de uma formação não formalizada.

A configuração de atores envolvidos na formação contínua em cada país poder público central e regionais, indivíduos, sindicatos e empresas - se caracteriza por uma figura central inversa: na Alemanha, a do individuo; na França, a da empresa. Paradoxalmente, na Alemanha, a intervenção do Estado visa facilitar a expressão da demanda individual; na França , ela procura estimular as despesas de formação das empresas. Todavia, esta inversão de ótica não poderia mascarar um fato persistente: na Alemanha, a empresa aparece como uma instância de formação que comporta agentes especializados na definição dos programas de formação e seu controle, o que não é o caso na França. Isto quer dizer que, num caso, a empresa é um agente de formação que dispōe de um conjunto de pontos de vista e de práticas pedagógicas constituídas, ao passo que, no outro caso, a pedagogia permanece uma tarefa de organismos e de agentes especializados que a empresa utiliza. Enfim, um outro fato geralmente desconhecido, inclusive na análise do LEST, e aqui trazido à luz: o estatuto dos operários não qualificados. $\mathrm{Na}$ Alemanha, esta categoria social não tem acesso à formação contínua, ao passo que na França ela é objeto de políticas específicas elaboradas em sua intenção (Ginsbourer er Alii,1992).

Para concluir, acrescentaremos que as pesquisas centradas nas diferenças homens-mulheres, omitidas nos trabalhos anteriores, levam a modificar a orientação das proposições estabelecidas a partir das observações circunscritas aos ramos da indústria e às instituições majoritariamente ocupadas pelos homens. Considerar o lugar da mulher no emprego (índice e formas de atividade segundo as diferentes idades), a posição que elas ocupam no sistema educativo, os tipos de estudos aos quais têm acesso e que elas privilegiam na França e na Alemanha, obriga a modular as interpretaçōes feitas do sistema dual, instrumento de mobilidade profissional e social. Expressão de uma realidade no masculino, a asserção perde toda a validade no feminino. Diante do exame dos trabalhos conhecidos até hoje, saber se as formas escolares favorecem ou não o acesso das mulheres às áreas de formação mais prestigiadas é a hipótese lançada (Marry, 1992 e 1993). 
A análise comparativa demonstra ser, como se vê, um dos modos de investigação mais fecundos neste campo. Um corpo de conhecimentos tende assim a se organizar através de deslocamentos de ângulos de abordagem sucessivos. Num país como a Gră-Bretanha, onde o debate social sobre a formação e a eficácia econômica é particularmente vivo, as comparações internacionais são desenvolvidas de forma particular (Ryan,1991).

\section{Conclusão}

O exame da literatura faz ver a fecundidade dos trabalhos empíricos realizados neste domínio. Destaca também que as análises e interpretações dos resultados, das informaçōes e dos conhecimentos produzidos dificilmente se deixam somar. É porque a própria natureza deste campo de pesquisas, o fato de relacionar duas esferas de atividades diferentes, obriga a isolar aspectos e momentos num conjunto de relações demasiadamente vastas para manterem-se. Além disso, a força do questionamento social se impöe tanto mais facilmente quando a pesquisa é recente a ele, condições que não favorecem uma integração das análises em quadros experimentados. Deste ponto de vista, os economistas parecem manifestar uma capacidade maior do que os sociólogos em confrontar seus enunciados e torná-los coerentes. A maior parte das perspectivas desenvolvidas pelos sociólogos se inscrevem, algumas vezes de forma indireta, numa tradição de análise das desigualdades sociais, da discriminação - hoje em dia pensada em termos de exclusão - ou da socialização, perspectiva que conhece atualmente uma recrudescência de interesse.

De maneira mais geral, em resposta ou como eco aos discursos que afirmam que a formação está no centro das transformaçōes sociais, os resultados das investigações conduzidas por uns e outros convidam a ter mais circunspeção. Sem dúvida, as atividades de formação ocupam um amplo espaço nas sociedades desenvolvidas, particularmente na França; sem dúvida, elas se desenvolvem correlativamente à reestruturação do emprego, às mudanças de organização do trabalho, mas também em resposta a problemas de coesão social, de coabitação das comunidades. Porém, na observação, parece que o domínio de atividade denominado formação abrange um conjunto de prática muito heterogêneas segundo os lugares onde são exercidas. Estas ações se realizam, de um lado, em organismos especializados - que dependem da autoridade do Estado, das organizações profissionais de empregadores ou ainda de associações - e, de outro lado, nas empresas. Os quadros gerais que as definem - por exemplo, em termos de tempos e de lugares são geralmente negociados pelo Estado, pelas organizações representativas dos empregadores e dos assalariados, revelando claramente que essas ações contribuem para definir relaçōes salariais. São observações que tendem a assentar nossa hipótese segundo a qual uma atividade de formação se organiza ao lado da atividade educativa realizada na instituição escolar e dela tende a se autonomizar. $\mathrm{Na}$ verdade, poderiamos mostrar que estes dois tipos de atividades, uma e outra em extensão, estabelecem relaçōes de concorrência cada vez mais manifestas. A organização dos processos de transição da escola para o emprego, o desenvolvimento da formação contínua nas empresas e a instauração de modos de formação 
em alternância engendraram a constituição de um meio que, por ser heterogêneo, tende a enfatizar que sua atividade serve ao interesse geral. Entretanto, se o lugar e o papel das instituições de formação e de inserção têm sido sublinhados, eles não foram objeto de análises específicas a exemplo das investigações conduzidas em torno das instituições escolares (Briand e Chapoulie, 1993). Certamente, esta perspectiva não é imediatamente transferivel para o campo da formação que não é tão fortemente institucionalizado quanto a escolarização. Os arranjos institucionais que constituem o campo da formação não possuem a estabilidade e nem a coerência da instituição escolar. Em matéria de formação, o uso do plural é uma necessidade inevitável. Não obstante, opções por perspectivas deste tipo obrigariam a discutir a atividade de formação, que permanece com muita freqüência aclimada, e contribuiriam para a emancipação das categorias de análise das Ciências Sociais das teses afirmadas pelos responsáveis políticos e econômicos que dão forma aos diversos organismos de formação. Sendo assim, uma tal atividade poderia ser questionada em suas formas e conteúdos para analisar as diferentes categorias de ações designadas sob seu nome, de acordo com os lugares onde elas se desenrolam, os públicos aos quais se dirigem e os agentes que as realizam.

Inversamente, também é preciso sublinhar que as observações feitas a respeito das práticas das empresas não permitem sustentar sem reserva a tese de uma autonomização da formação em relação ao trabalho. Se forças sociais agem para conceber e organizar as ações de formação fora do âmbito do trabalho, no seio de organismos especializados, outras forças agem para manter e controlar seu desenrolar em (ou na proximidade de) situações de trabalho. Por isso, deixaremos esta hipótese em aberto para submetê-la ao exame de investigações empiricas apropriadas.

\section{Notas do revisor da tradução}

Baccalauréat: Na França, grau universitário conferido após os exames de conclusâo dos estudos secundários.

Brevet: Na acepção empregada no texto, diploma ou certificado do primeiro ciclo do ensino secundário que sanciona uma formaçăo de operário, técnico ou empregado qualificado.

Collège: Na França, estabelecimento de primeiro ciclo do ensino secundário.

Maîtrise: Na França, grau universitário que sanciona o segundo cíclo do ensino superior (obtido no quarto ano de estudos universitários). 